\title{
Leadership Strategies in Mobile English as a Second Language Training
}

Djenana Jalovcic, Linda McCloud-Bondoc, and Anthony Ralston

Athabasca University, Canada

\section{Abstract}

This paper reviews a pilot mobile learning project for English as a Second Language implemented by a unimodal distance education institution to present an argument favouring the use of a distributed leadership approach for sustainability of the project. The authors' position is grounded in the literature which suggests that distributed leadership in mobile and distance learning can provide a framework for sustainability of this project.

Keywords: Distributed leadership theory; mobile learning; distance learning 


\section{Leadership Strategies in Mobile ESL Training}

Imagine you are a newly arrived immigrant working in Alberta's oil fields. You know some English, but when your co-workers start to joke around, you can't follow the conversation. More importantly, when you need to write a report for the next shift or to your boss, fill out a form for health insurance, or send an email to a government agency, you are not sure you are communicating clearly. You would like to improve your grasp of English, but you are working long hours, and you don't have internet access in your apartment, which eliminates online courses as an option.

This was the kind of problem that the team at a unimodal distance education institution set out to solve when they designed the English as a Second Language (ESL) mobile learning (mLearning) project, a pilot project using mobile devices as the ESL training delivery mode to non-native English speakers who required grammar skills to improve their English.

In this paper, the authors will argue that the social need that prompted the creation of this project still exists and, thus, there is a need to continue it and make it sustainable. Further, we will argue that distributed leadership (DL), with its emphasis on collaboration, skill sets, and recognition of leadership regardless of formal position, is a model that lends itself to distance learning projects in general and to extending and sustaining this project in particular.

To provide a basis for our argument, we describe the background to the pilot project including the learning environment, its audience, and the methodology of the delivery used. Secondly, the constructs related to distributed leadership theory are explored, including definitions and examples from the literature on the effectiveness of this leadership approach. Its potential application to this project is discussed. Thirdly, this investigation of the pilot project includes evidence from the literature as to the utilization of mobile learning and associated methodologies that form the framework for learners' access to flexible learning. Finally, the authors discuss opportunities in distance education and the properties of distributed leadership.

\section{The ESL M-Learning Project}

\section{The Social Need}

For decades now, Canada has been an increasingly popular destination for immigrants and foreign skilled workers. However, not all immigrants have the ability to speak English or French. In fact, Statistics Canada (2011) reports that among the recent immigrants that arrived to Canada between 2006 and 2011, 9.0\% were not able to converse in either of the official languages. 
At the same time, newcomers are under pressure to find jobs quickly, and integrate economically and socially; the key to their successful integration is their ability to speak English. Those who do not have basic English grammar skills have difficulties developing their listening, speaking, and writing skills, consequently limiting their ability to communicate on the job and in social situations. In addition, faced with pressures of settlement in a new country, new jobs, and learning English, many newcomers do not have time to devote to improving their language skills. This poses a social problem, as without basic English language skills, opportunities for new immigrants and skilled workers to fully contribute to and participate in Canadian society remain limited.

\section{An mLearning Solution: Delivering ESL Grammar Training}

In order to address this problem and test the viability of mLearning as a solution, a project was initiated by a unimodal distance education institution. This education institution offers programs where faculty and students are distributed geographically. The institution itself has a bicameral governance structure with a Board of Governors sharing academic governance with a governing body called the General Faculties Council. However, many projects, like this one, are undertaken by small teams that function with relative autonomy without a clearly defined leadership structure or strategic plan (M. Ally, personal communication, February 2, 2014). In the last 10+ years, the institution has been in transition from a correspondence stage of distance education to a networked education model (Beaudoin, 2003) which includes developing e-learning resources such as the one under discussion.

It is within this institutional context that this mLearning ESL training program was developed. The project was implemented in collaboration with community partners, including a small community college, a faith-based newcomer organization, and a local church community, all of whom already offered face-to-face ESL classes to newcomers. The team also included members from the university's distance education academics, its library, and its research centre. This research team, led by the institution's associate vice president, research, included a content expert, computer expert, researcher, team leader, and editor. It worked as a virtual team. The project had very good institutional support under the leadership of the AVP Research (M. Ally, personal communication, February 2, 2014).

The main purpose of the project was to develop and assess the effectiveness of ESL learning by using mobile devices in helping newcomers and ESL learners acquire English grammar, and to share the results with a wide audience. The program was designed to allow ESL learners to use their mobile phones, tablets, and computers to access ESL lessons and improve their knowledge of English grammar. Eighty-six lessons posted at the education institution website were based on one of the best selling English grammar and exercise books released as open source (Ally, Schafer, Cheung, McGreal, \& Tin, 2007). The website had a device recognition system built in, so the program automatically recognized the device and enabled learners to use the 
appropriate version, and access it anytime, anywhere. Learners did not need to take time off work to take English lessons as they were able to access the program on their mobile devices while travelling, on the job, or at home on their computers.

The program was open access, flexible, asynchronous, highly interactive, individualized, and self-paced, with built-in self-assessments and immediate feedback for learners to evaluate their own progress. The lesson design was informed by behaviourism with skill-and-drill, self-assessed learning methods aimed at improving language skills. In a follow-up review of the project, Ally et al. (2007) reported that participants improved their English grammar skills from 15/20 in pre-test to 17.7/20 and 18/20 in a post-test and retention test respectively. Ninety-four percent of participants agreed or strongly agreed that this technology provided flexibility for them to learn anywhere and at any time, while $78 \%$ agreed or strongly agreed that the use of this type of technology could increase access to learning materials, and that it is easy to access and navigate the course materials (Ally et al., 2007).

Years after the pilot project was completed the traffic on the project website is still monitored by using an online database tracking system. Statistics were collected that measured a number of factors including student use, type of device, length of time, and geographical region. One of the project leaders provided a site-metrics report on downloads and worldwide use of the ESL website that showed that in 2012 over 57,000 visitors visited the website 65,721 times (1.15 visits per visitor) during which they downloaded 142,708 pages (2.17 pages per visit) and had 699,568 hits (10.64 hits per visit). The biggest number of pages was downloaded by visitors from the United States (27,964 pages), Canada (11,870 pages), and the Philippines (6,921 pages), followed by Great Britain, Spain, Turkey, Mexico, and Denmark. The results after the project had officially ended indicate that $83 \%$ of students used a Windows operating system and less than $1 \%$ of students used a mobile device to access the learning material.

In addition to ongoing use of the website, a number of other mLearning, ESL projects were developed based on this one (M. Ally, personal communication, February 2, 2014) making this project a success from the point of view of initial uptake and use of the learning tool.

However, although the project was a success, review of the project also suggests further opportunities for distance education. For example, the Edmonton Journal (2007) published an article by Gerein about the project and stated that "nearly 70 per cent of the immigrants who tried the technology in the pilot project said they found it improved their learning experience, although they indicated it would never serve as a substitute for a teacher in a classroom" (para. 7), suggesting that students did not see it as the only tool for ESL learning. In addition, the metrics report suggests that after the project was completed only one out of five students who visited the site actually accessed the lessons and that most students accessed the site through their PC rather than from a mobile device (J . Dutton, personal communication, March 5, 2014). This review, then, suggests 
opportunities to 1) draw more students into the site and 2) help students make full and independent use of the mobility offered by this learning tool by sustaining this project.

The project concluded and presently does not have long-term financial, administrative, or institutional support to sustain its continuation. However, after its completion, this learning tool was left in cyberspace to live its life more or less on its own. The project team addressed a social problem and tested a solution that worked, but, as with many other research projects, that meant the end of active engagement. Responsibility to translate this knowledge to action, other than in conference presentations and journal papers, and maximize the potential of the project for students by making it sustainable currently rests with knowledgable users. Arguably, the lack of a long term vision for the post-piloting period and the lack of planning and leadership strategies have impacted the sustainability of the project. As it stands now, then, it provides an opportunity to make it sustainable over the long-term by using a different leadership model.

Thus, the social problem of helping new immigrants improve their English was addressed in part by this mLearning project, but more can be done. There still remain opportunities to improve students' full use of the learning tool, and to make the project sustainable in its current form. However, these distance education opportunities can only be realized with a form of leadership that can bring together the right leaders and team members from various disciplinary backgrounds and from varying institutional cultures, gain their buy in and collaboration, plan for sustainable funding, implementation, and administration, and provide more extensive research on the effectiveness of the learning tool.

\section{The Constructs of Distributed Leadership}

This section will define and provide examples from literature regarding distributed leadership and its relation to distance education, as well as its potential application to this project to ensure its sustainability. First it will define distributed leadership, give examples from the literature, and finally recommend future uses of the distributed leadership theory in relation to the ESL pilot project.

The distributed leadership theory as it relates to distance education is commonly defined as an approach that includes networking, collaboration, instilling a common vision, allowance for member-leader actions, and empowering members to adopt new paradigms of working (Jameson, Ferrel, Kelly, Walker, \& Ryan, 2006; Keppell, Dwyer, Lyon, \& Childs, 2001; Fahlman, 2012). In academic, distance education institutions, distributed leadership is defined as a collective approach in which leaders encourage all team members to contribute to a strategic vision (J ameson et al., 2006; Keppell et al., 2001; Fahlman, 2012). 
Humphreys (2010) draws our attention to the work of Spillane and Duignan, two eminent researchers on the topic. Spillane, as referenced by Humphreys (2010), is of the opinion that distributed leadership can take place with different people at different times and is not reliant on the traditional top-down model. The workplace setting for this type of leadership is dependent on interplay between all the members of the organization or department involved in the project(s). On the other hand, Duignan points out that a distributed model in a traditional hierarchical paradigm should include an emphasis on trust that is furthered through a culture that allows people to be leaders. Palmer, Holt, Gosper, Sankey, and Allan (2013) also remind us that a useful generic definition of distributed leadership is provided by Harris (2009):

Distributed leadership essentially involves both the vertical and lateral dimensions of leadership practice. Distributed leadership encompasses both formal and the informal forms of leadership practice within its framing, analysis and interpretation. It is primarily concerned with the co-performance of leadership and the reciprocal interdependencies that shape that leadership practice. (p. 5)

Siemens (2006) speaks about the online learning environment as one where "Organizational structures are becoming increasingly decentralized, instruction more learner-centered and self-directed, as traditional campuses are giving way to for-profit institutions and partnerships" (p. 1). Leaders in administrative positions are facing the ever increasing need to develop and communicate a vision to the institution. The effective distributed leader will focus on how staff do things and how they interact rather than what a leader does. He goes on to state that any advocacy for this leadership approach involves roles and responsibilities that are divided equally amongst the staff in order to create a democratic environment. This approach to leadership is further supported by Gressick and Derry (2010) in a study that finds leadership is a social activity that involves work by group members that will influence or motivate other group members.

In the case of distance education, the use of a distributed model in distance learning or e-learning presents a unique set of circumstances when it comes to leadership (J ameson et al., 2006). These authors form their options based on e-learning development settings where teamwork, collaboration, and projects that have multiple concurrent timelines can benefit from a more common approach rather than a transactional or conservative philosophy of leadership. The authors claim that distributed leadership can offer the flexibility required to adapt to distance learning delivery. They emphasize that coordination and collaboration approaches in a team-based environment where the realities of distance learning demands that constant communication and self-leadership.

The use of a distributed leadership approach for online learning is typified by Palmer et al. (2013) in their discussions surrounding online learning environments (OLEs). They 
maintain that leadership is paramount given the nature of online learning. Specifically, the intersection of IT systems, centres for teaching, and faculties associated that connect with OLEs results in complicated organizational structures and therefore a distributed model would provide an environment whereby all the differing stakeholders could be brought together under collaborative and information sharing themes. In the case of OLEs, the authors claim that distributed leadership may be a more effective method to deal with the realities of the need for a high level of collaboration amongst parties who are responsible for online learning albeit technical or content aspects.

Further evidence from Fressa (2009) who states that distributed leadership has increased in popularity, but with overlapping terminology and synonyms such as shared leadership, democratic leadership, or collaborative leadership. Regardless of the terminology used, this approach can create opportunities for increased capacity through leadership activities extended across different people and positions within organizations, thus the resulting synergy is stronger than the individuals themselves.

Keppell et al. (2001) also define distributive leadership as an approach that focuses on collaboration, shared purpose, responsibility and recognition of leadership irrespective of role or position within an organization. The authors described a project where distributive leadership had been utilized as a change agent. Teachers embarked in a professional development activity associated with building capacity for re-designing courses for a blended delivery. The study noted that the teachers took on the roles of distributed leaders resulting in a more effective process for change in curriculum design.

\section{Distributed Leadership and ESL mLearning: Building Bridges}

\section{Opportunities.}

Distributed leadership theory suggests that DL is capable of creating collaborative networks and bringing leaders together under one strategic vision. Thus, this kind of model is ideal to extend the mLearning ESL project because it would allow leaders from a number of institutions and organizations to work together, creating bridges among existing and potential partner institutions. In addition, with its focus on self-leadership and distributed responsibility, and its ability to create synergies, DL would provide a way for partner institutions to collaborate to meet the needs of learners by bringing administrative, technical, and teaching resources together from a variety of disparate organizations. A leadership model such as DL that emphasizes collaboration and leverages the strengths of individuals would help to establish the necessary organizational structures, both inside and outside the partner organizations, to make this project sustainable. Since a DL model defines leadership in terms of what people do rather than people's positions (Spillaine, Halvorsen, \& Diamond, 2001), it provides an opportunity to draw on the most appropriate people from all organizations, whether or not they hold formal leadership positions.

The flexibility of DL makes it suitable for this project, as it would facilitate the strengthening of existing ties between the lead distance education institution and the 
partner organizations by recruiting the same people from the partner organizations engaged in the original project. It would allow easier recruitment of team members from smaller organizations that might not otherwise have the leadership resources to make this project sustainable. This flexibility would enable community organizations that already deliver ESL instruction to use their expertise and knowledge of their own students to contribute to the design and delivery of the program. At the same time, it would allow leaders at the unimodal distance education institution who have expertise in mLearning and distance education to contribute.

A DL model would also suggest specific qualities that leaders would need to make this project sustainable over the long term. For example, DL's emphasis on empowering numerous leaders to work collaboratively and build engagement suggests that all leaders in this project need to be chosen for their flexibility and ability to adapt. The DL model makes different demands of leaders depending on the situation and circumstances (Spillane, 2010) and may even demand that leaders adopt different roles throughout the project. The positive side of this approach is that it can result in shared responsibilities and allow a more democratic flow of power, but leaders who participate in this project must also be prepared to adapt to the needs of the situation, adopt different roles, and share responsibility and power.

In the extension of this project, then, with the need for leaders in a number of disparate institutions, a DL model suggests what kind of leaders are needed for this project to succeed: ones who have well-developed interpersonal skills, a proven ability to work collaboratively, and who can function with a high level of cooperation in an atmosphere where members contribute knowledge and experience (Fahlman, 2012), and where leaders possess the skills and flexibility to fill a number of roles.

\section{Challenges.}

In addition to suggesting the specific qualities needed in leaders, the DL literature review above also suggests a number of challenges that these leaders may encounter in making this project sustainable. For example, while DL can integrate leadership and create "reciprocal interdependencies" (Harris, 2009, p. 58) it is necessary for authority and decision-making to be distributed along with the leadership role. This can be a challenge for traditional organizations because, to introduce DL, hierarchical organizational models must adapt to more "lateral, flatter decision-making processes" (Hargreaves, 2007, as cited in Harris \& Spillane, 2008, p. 31). In fact, some researchers suggest that the DL approach includes an inherent danger of devolving leadership responsibilities without also devolving political power (Maxcy \& Nguyen, 2006). Thus, if leaders on this project without formal leadership roles are not invested with authority by their institution or organization, there is a danger that they could be disrespected and ignored (Timperley, 2005), thus threatening the success of the project.

There is also the danger that leadership shared across organizations could present challenges to institutional/organizational buy in. Jones and O'Shea (2004, as cited in 
Jameson et al., 2006) suggest that educational institutions are slow to change leadership styles to accommodate the distributed, flexible, and democratic partnership requirements of e-learning projects trialing new software, tools, and learning innovations, such as this project. In this case, where leadership within the lead unimodal distance education institution and other partner organizations is hierarchical, there could be conflicting loyalties between internal and external structures. In other words, in extending this project, the distributed leadership could challenge existing lines of authority both within the lead distance education institution and within partner organizations and, thus, endanger buy in from partner institutions.

A DL model suggests that to sustain the use of this mobile, ESL grammar resource, team members from all partner institutions and organizations should be selected carefully, based on their areas of expertise and their abilities to share a vision, leadership, and authority. This model also highlights the need for each organization to buy into the project, this model of leadership, and to invest their team members with the authority and resources necessary to complete the project.

\section{mLearning and distributed leadership.}

Some researchers see mLearning, that is, the "use of mobile or wireless devices for the purpose of learning while on the move" (Park, 2011, p.79), as the ideal solution to overcome barriers such as those faced by the immigrant group at the centre of this project. For example, Ally (2012) suggests that mLearning can overcome barriers to learning such as distance, poverty, and lack of resources by making education more accessible and affordable in part because "mobile technologies allow people who do not have computers to access education" (p. 4). Park (2011) affirms these advantages of mLearning, arguing that mobile technology makes ubiquitous, or "u-learning" (p. 81), possible by freeing learning from any particular location, device, or setting. Mobile learning can also decrease isolation between learners and help them to create personal learning environments (PLE) by combining various Web 2.0 technologies and allowing users to share knowledge and interact (Attwell, Cook, \& Ravenscroft, 2009). Thus, mLearning has the advantages of delivering learning in a flexible, individualized manner, where and when students want and need it. It includes a wide range of flexibilities in the kind of device used, the platform used to deliver learning, and the learning context, reducing barriers of time, cost, and technical expertise.

However, if mLearning has advantages, it also has disadvantages. For example, Ally (2012) identifies a number of barriers to mobile learning, including a lack of open educational resources (OER) and a lack of expertise in mobile learning. In addition, in his evaluation of this project, Ally (2012) found that students "indicated that the use of mobile technology for ESL would be a good supplementary medium for learning” (p. 5) (emphasis added). For this project, this finding suggests that mLearning would be suitable for informal learning, but not for formal, credentialed learning and suggests that a lack of learning support could be a barrier to learning. 
Park (2011) also suggests some limitations of mobile devices and mLearning, including small screen size, distractions in the environment, and limitations of the software. This author's work in creating a typology for mLearning suggests that, in order to benefit from mLearning, students have to be highly motivated and independent learners because there is little instructor-learner interaction while the learner has a great deal of control over the delivery of the content. In this situation, Park (2011) suggests that technical support is important to the success of such projects and that "instructional designers or institutional distance learning support staff should pay special attention to the creation and management of a knowledge database, including well-organized learning materials such as lecture (audio or video) files, reading materials, and vocabulary databases" (p. 93). In other words, any mLearning project must include technical and instructional designer support, and adequately designed learning objects, databases, and learning materials.

Mobile learning comes with a distinct set of circumstances, such as distributed learners and workforce, a lack of face-to-face communication, and a need for more and varied departments and disciplines to work together. For example, an online learning environment might require the collaboration and coordination of various areas of expertise, such as technical, administrative, design, and organizational. Organizations, particularly those involved in distance and distributed education, are becoming more decentralized. Thus, in distance education as a whole, there is a need for collaboration and flexibility in roles which suggests a move away from traditional top-down leadership models.

Mobile learning then adds to the usual demands of an online environment because of the increased anytime-anywhere nature of the learning. Administration, technical, and teaching departments have to be collaborative to create and maintain such environments. Learning objects have to be designed for new audiences who can only begin to access learning materials when they are delivered on mobile devices. Mlearning objects have to be intelligible not only to traditional distance delivery students but also across a greater variety of nationalities, cultures, and possibly even languages. This added level of complexity makes flexibility and collaboration with people "on site and on the ground" even more essential in implementing an m-learning project. In sum, then, distance education in general, and m-learning in particular, can benefit from a leadership model that emphasizes collaboration, flexibility, and a move away from a traditional top-down power structure.

Some of the features of DL when it is successfully implemented make it suitable to provide this flexibility. This model offers the ability to

- allow leadership roles to cross traditional departmental, cultural , disciplinary, and professional boundaries;

- invest authority and control in people according to the demands of the project and not according to their formal positions; 
- include both formal and informal power structures;

- $\quad$ avoid top-down power structures;

- connect the responsibility for successful leadership with practical and professional expertise;

- move team members in and out of leadership roles as the project requires.

The pilot project was successful in demonstrating that mLearning was a good solution for newcomers to Canada to learn English grammar skills anytime, anywhere. In order to sustain it, further involvement of participants in the pilot project is required at both leadership and technical levels. We have argued that by using the DL model this could be achieved. If extended, it is expected that ongoing changes to the content and technology upgrades will be required. Therefore, continuous involvement of a technical team of IT specialists, mLearning instructional designers, and content experts will be necessary to support learners. A leadership team will ensure that the technical team is involved as well as all other partners. Because DL is a model where leadership can take place with different people at different times and is not reliant on the traditional topdown model (Spillane, as cited in Humphreys, 2010), it has the potential to bring together a technical team to support learners and a leadership team to reach out to more learners in order to sustain this multi stakeholder program.

\section{Conclusion}

Immigrant workers continue to flood into the Canadian labor market. However, their inability to communicate clearly in English constitutes a social problem because it tends to isolate them socially and to make them more vulnerable to exploitation (Barneston, 2012). And while the mLearning ESL project examined in this paper is a partial solution to this problem, to fully realize its potential, a new project team needs to be assembled to reach more of these workers on a long-term basis and to realize further educational opportunities identified by the pilot project.

In this paper, we have argued that a DL model would promote the necessary buy in from a variety of institutions and bring together the key parties in order to create a strategic plan to carry the project forward. In particular, we argue that a DL model is especially useful when mLearning is involved since these kinds of projects require a high degree of leadership from many stakeholders in a collaborative effort to reach the necessary goals of the projects at hand. The research on this leadership model suggests practical considerations to make this project sustainable, such as consideration of the interpersonal qualities that the distributed leaders would need to support collaboration and of the composition of a team that includes content experts, learning designers, internet technology experts. 
A distributed leadership (DL) approach is meant to be non-hierarchical in nature and therefore promotes collaboration and ethical practice. In the context of mobile learning such as the English as a Second Language project, a DL model promotes leadership as an element of a group or network of interacting individuals. The complexities of mobile learning and distance learning demand high levels of collaboration, stakeholder management, quality control mechanisms, and a managed infrastructure of technology.

Considering this distance form of delivery mode, a DL model, by nature, suggests a degree of open and transparent communication strategy in terms of leadership, a project management strategy that outlines the design, development, and delivery of learning on mobile devices, and the fostering of an organizational dynamic which conveys the philosophy that the sum of the parts is greater than the individual, but includes room for leadership action by all individuals in the project. In addition, the DL approach would seek to draw on the expertise and strengths of the organizational group involved in mobile learning thereby cultivating a shared common view of both the purposes of the team and its means of working.

If all partner organizations in this project can move away from a top-down, hierarchical decision-making model, invest team members with authority to make decisions, and engender trust among team members and partner organizations, then the DL model is well suited to making this project sustainable. It would provide an environment whereby leadership would be fostered in teams that would collaborate in order to innovate and then implement the designs necessary for mobile delivery to workers, who would benefit from such a project. 


\section{References}

Ally, M. (2012). Mobile learning: The equalizer in education. La Educ@ción Digital Magazine, 147. Retrieved from http:// www.educoea.org/portal/La Educacion_Digital/ 147/index.html

Ally, M., Schafer, S., Cheung, B., McGreal, R., \&Tin, T. (2007, October 16-19). Use of mobile learning technology to train ESL adults. Proceedings of the 6th Annual International Conference on Mobile Learning, Australia (pp. 7-12). Retrieved from http:// www.mlearn.org/mlearn2007/files/mLearn_2007_Conference_Pr oceedings.pdf

A uni-modal distance education institution. (n.d.). Mobile ESL [Website]. Retrieved from http:/ / eslau.ca/

A uni-modal distance education institution (n.d.) About AU: Governance [Website]. Retrieved from http:// www.athabascau.ca/ aboutau/ governing.php

Attwell, G., Cook, J ., \& Ravenscroft, A. (2009). Appropriating technologies for contextual knowledge: Mobile personal learning environments. Best Practices for the Knowledge Society: Knowledge, Learning, Development and Technology for All. Retrieved from http:/ / www.springerlink.com/index/ u118178m84798672.pdf

Barneston, B., \& Foster, J . (2012). Foreign migrant workers in Alberta. Abstracts from the Canadian Political Science Association 84th Annual Conference, Canada, p.7. Retrieved from http:// www.cpsa-acsp.ca/ pdfs/2012Abstracts.pdf

Beaudoin, M. F. (2003). Distance education leadership for the new century. Online J ournal of Distance Learning Administration, 6(2). Retrieved from http:/ / www.westga.edu/ distance/ ojdla/ summer62/ beaudoin62.html

Collis, B., \& Moonen, J . (2011). Flexibility in higher education: Revisiting expectations. E-LIS Repository. Retrieved from http:// eprints.rclis.org/ 16648/

Fahlman, D. (2012). Educational leadership for e-learning in the healthcare workplace. The International Review of Research in Open and Distance Learning, 13(2), 236-246. Retrieved from http:/ / www.irrodl.org/index.php/irrodl/article/ view/ 1122/ 2150।

Flessa, J . (2009). Educational micropolitics and distributed leadership. Peabody J ournal of Education, 84, 331-349. doi:10.1080/01619560902973522\ 
Gerein, K. (2007, May 18). Lessons by cellphone a hit. The Edmonton J ournal. Retreived from http:// www.canada.com/ edmontonjournal/news/local/story.html?id=8e7 $\underline{\text { 90572-819c-4074-b4d6-4a94a44b4fc2\&k=89020 }}$

Gressick, J ., \& Derry, S. (2010). Distributed leadership in online groups. International J ournal of Computer-Supported Collaborative Learning, 5(20), 211-236. Retrieved from $\underline{\mathrm{htt} p: / / 0-}$ eds.a.ebscohost.com.aupac.lib.athabascau.ca/ eds/ pdfviewer/ pdfviewer?sid=98 4058de-b389-4d6c-a2bf-

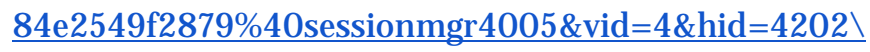

Harris, A. (2009). What is distributed leadership? (Unpublished manuscript). London Centre for Leadership in Learning, Institute of Education, London, U.K. Retrieved from http:// digitalcommons.unl.edu/managementfacpub/37/

Harris, A., \& Spillane, J . (2008) Distributed leadership through the looking glass. British Educational Leadership, Management \&Administration Society, 22(1), 31- 34. doi: 10.1177/0892020607085623

Humphreys, E. (2010). Distributed leadership and its impact on teaching and learning (Doctoral dissertation). National University of Ireland, Maynooth. Retrieved from http:// eprints.nuim.ie/2041/八

Jameson, J., Ferrel, G., Kelly, J ., Walker, S., \& Ryan, M. (2006). Building trust and shared knowledge in communities of e-learning practice collaborative leadership in the J ISC eLISA and CAMEL lifelong learning projects. British J ournal of Educational Technology, 37(6), 949-967. Retrieved from http:// 0eds.a.ebscohost.com.aupac.lib.athabascau.ca/ eds/ detail?sid=984058de-b389$\underline{4 d 6 c-a 2 b f-}$ 84e2549f2879\%40sessionmgr4005\&vid $=4$ \&hid $=4202 \&$ bdata $=J$ nNpdGU9ZWR zLWxpdmU\%3d\#db=eric\&AN=EJ 746070

Keppell, M., Dwyer, C., Lyon, B., \& Childs, M. (2001). Transforming distance education curricula through distributive leadership. Research in Learning Technology, 18(3), 9-21. Retrieved from http:// sloanconsortium.org/jaln/v15n4/transforming-distance-educationcurricula-through-distributive-leadershipl

Maxcy, B. D., \&Nguyen, T. S. T. (2006). The politics of distributing leadership reconsidering leadership distribution in two Texas elementary schools. Educational Policy, 20(1), 163- 196. doi:10.1177/ 0895904805285375

Palmer, S., Holt, D., Gosper, M., Sankey, M., \&Allan, G. (2013). Exploring distributed leadership for the quality management of online learning environments. 
European J ournal of Open, Distance and E-Learning, 16(2), 61-75. Retrieved from http:/ / www.eurodl.org/ ?article $=588$ /

Park, Y. (2011). A pedagogical framework for mobile learning: Categorizing educational applications of mobile technologies into four types. The International Review of Research in Open and Distance Learning, 12(2), 78- 102. Retrieved from http:/ / www.irrodl.org/ index.php/irrodl/article/ view/ 791

Prestera, G.E. \& Moller, A.L. (2001). Facilitating asynchronous distance learning: Exploiting opportunities for knowledge building in asynchronous distance learning environments. Proceedings of Mid-South Instructional Technology Conference, Middle Tennessee State University, Pennsylvania, United States. Retrieved from http:/ / www.docstoc.com/ docs/ 100907362/ FacilitatingAsynchronous-DistanceLearning WxWXS\&ContentCustomer=dGJ yMPGrrk2zr7FJ uePfgeyx44Dt6fIA

Siemens, H. (2006). Distance education leadership: Employing the ETIPs model to assess leadership practices in support of e-Learning. Proceedings of the World Conference on E-Learning in Corporate, Government, Healthcare, and Higher Education, United States, 2006(1), 559-559. Retrieved from http://0www.editlib.org.aupac.lib.athabascau.ca/ p/23750/

Spillane, J . P. (2005). Distributed leadership. The Educational Forum, 69, 143-150. Retrieved from http:// www.tandfonline.com/doi/abs/ 10.1080/001317205089846781

Spillane, J . P. (2006). Distributed leadership. San Francisco: J osey-Bass.

Spillane, J. P., Halverson, R., \& Diamond, J . B. (2001). Investigating school leadership practice: A distributed perspective. Educational Researcher, 30(3), 23-28. Retrieved from http:// www.jstor.org/ stable/ 3594470

Statistics Canada. (2011). National household survey: Immigration and ethnocultural diversity in Canada. Retrieved from http:/ / www12.statcan.gc.ca/ nhsenm/ 2011/as-sa/ 99-010-x/ 99-010-x2011001-eng.cfm

Timperley, H. S. (2005). Distributed leadership: Developing theory from practice. J ournal of Curriculum Studies, 37(4), 395-420. doi:10.1080/ 00220270500038545

White, G. (2004). E-learning: Australia's achievements in education and training. VOCED plus: The international tertiary education research database. Retrieved from http:// www.voced.edu.au/ content/ngv17802। 


\section{Athabasca University $\mathbf{I}$}

(c) 